\title{
Tax revenues, fiscal corruption and "shame" costs
}

\author{
Roy Cerqueti \& Raffaella Coppier \\ University of Macerata \\ Department of Economic and Financial Institutions, \\ Via Crescimbeni, 20 - 62100 - Macerata \\ E-mail: $\{$ roy.cerqueti, raffaellacoppier\}@unimc.it
}

May 22, 2009

\begin{abstract}
In this paper we explore tax revenues in a regime of widespread fiscal corruption in a static framework. We prove that the relationship between the tax rate and tax revenues depends on the relevance of the "shame effect" of being detected in a corrupt transaction. In countries with a "low shame" effect, tax revenues grow as the tax rate increases. Moreover, there is a critical tax rate where the growth rate of tax revenues begins to reduce. In countries with a high "shame effect" tax revenues increase up to a threshold value and then decrease.
\end{abstract}

Keyword: Corruption, Evasion, Tax revenues.

JEL Codes: D73 H21 H26.

\section{Introduction}

Tax evasion and fiscal corruption have been a general and persistent problem throughout history with serious economic consequences, not only in transition economies, but also in countries with developed tax systems. Generally, corruption and evasion are two distinct phenomena, which can exist independently. But when tax authorities are dealing with the possibility of corruption they should consider the possibility of taxpayers who under-report their income bribing tax inspectors. It is widely agreed that tax evasion and corruption have several detrimental effects on the economy. The loss of tax revenues can, in fact, imply a reduction in public services; in addition, tax 
evasion and corruption can seriously harm economic growth (amongst others, Rose - Akerman, 1975, 1978; Shleifer and Vishny, 1993) and distort income distribution as individuals and firms may have different opportunities for evasion (Hindriks et al.,1999). Although there is extensive literature investigating the origins, effects and extent of evasion and corruption from both theoretical and empirical points of view, interaction between tax evasion and corruption has only been partially explored. It is, in fact, only recently that this relationship has been investigated in the literature. Although tax evasion can exist without corruption and corruption can exist without tax evasion, since bribery agreements can reduce deterrence of violation, the interaction between evasion and fiscal corruption is a relevant economic phenomenon when analyzing the behaviour of tax revenues.

In the pioneering model of Allingham and Sandmo (1972), the relationship between tax rates and evasion is ambiguous and depends on the utility function. A broader review of the literature reports more generally, that theoretical predictions of the effect of tax rates on evasion are dependent on the assumptions of the model (Slemrod and Yitzhaki, 2000). Fisman and Wei (2000) present a case study of tax evasion in China: they find that, on average, a 1 -percent increase in the tax rate leads to a 3-percent increase in evasion and, furthermore, this relationship is not linear: the evasion elasticity is larger at a high tax rate.

Chander and Wilde (1992) take into account the possibility of collusion between a tax evader and an official auditor whose cost of dishonesty is (relatively) low. Besley and McLaren (1993), Hindriks et al. (1999), and Mookherjee and Png (1995), deal with the issue of optimal remuneration of inspectors. Besley and McLaren (1993) compare three distinct remuneration schemes, which provide different incentives to inspectors: efficiency wages, reservation wages and capitulation wages. They characterize the conditions under which each scheme generates the greatest amount of tax revenues, net of administration costs. They show that the efficiency wage strategy may not be a good idea most of the time. In contrast, in our model, we do not consider the issue of optimal remuneration of inspectors as we assume that the inspector is paid a fixed wage. Hindriks et al. (1999) consider a model where all the actors are dishonest. They allow, however, for general remuneration schemes and, more importantly, for extortion. They show that, as well as losses in tax collection, the more bribes are collected, the more a tax inspector can resort to extortion in order to collect even more. In this case, the authors show that distributional effects of evasion and corruption are regressive, because the richest taxpayers have most to gain from evading taxes and are least vulnerable to extortion (as it is harder to credibly over-report their income). Finally, Mookherjee and Png (1995) also consider only corruptible agents, 
although they remove the exogenous matching of the auditor and the evader, which is often-assumed in the literature. They consider it a moral hazard problem since the inspector has to exert a costly non-observable effort for evasion to be disclosed.

All the models described analyze the relationship between tax revenues and the tax rate, and some of them (see Chander and Wilde, 1992 and Sanyal et al., 2000) show, as does our model, that there may be a possibility that an increase in the tax rate could actually decrease government revenues.

Our paper provides a study of the behaviour of fiscal revenues beyond where there is corruption, as we also consider the relevance of the "shame effect" linked to the possibility of the entrepreneur being detected and reported in a corrupt transaction. When bureaucracy is corrupt, a rise in tax rates starts off complicated strategic moves on the part of both taxpayers and inspectors. In a corrupt administration, in fact, a higher tax rate can represent the possibility of a higher negotiated bribe rate: this may increase the number of corrupt tax inspectors by overcoming the "shame" cost, while for taxpayers, a higher tax rate creates a greater incentive to pay bribes.

In our model, we demonstrate that the relationship between the tax rate and tax collection depends on the relevance of the "shame effect". In details, if the State wants to maximize tax revenues in a "low shame" country, it has to set a tax rate greater than a threshold value, because up to this value, the tax revenues increase - as the tax rate increases - at an increasing rate; in a "high shame" country, the State should set a tax rate equal to a threshold value because this value is a global maximum of tax revenues with respect to $t$. In both cases, there is fiscal corruption in the economy.

The paper is organized as follows. In Section 2 we present the model, describe the timing of the game and present the results. In Section 3 we discuss policy considerations. Section 4 concludes.

\section{The model}

Consider an economy producing a single homogeneous good $y$. The economy is composed of three players: controllers, tax inspectors and entrepreneurs. Tax inspectors cannot invest in the production activity and earn a fixed salary $w$. Entrepreneurs use their available capital in the production sector. The State monitors entrepreneurs' and tax inspectors' behavior through controllers, in order to weed out or reduce corruption, and fixes the level of the tax rate $t$ on the product $y$. The State uses its tax revenues to pay the tax inspectors' wages, and there is no space for financing public productive expenditure. We assume that taxation is not distorstive regarding input 
provision. Entrepreneurs produce $y$, with technology with constant returns to scale. Each entrepreneur is assumed below to have the same quantity of capital $k$. The production function of the good only depends on the capital and the natural state that may occur. Indeed with a probability $(1-\delta)$ production will be $y=a k$, while with a probability $\delta$ an adverse natural state will occur, production will not take place and the corresponding production will be $y=0$. The tax inspector, who checks whether the tax payment is correct, is able to tell which of the two natural states have occurred for each entrepreneur. It is common knowledge that the tax inspector ${ }^{1}$ is corruptible, in the sense that he pursues his own interest and not necessarily that of the State; in other words, the tax inspector is open to bribery. The tax inspector, in the case of the "good" natural state and in exchange for a bribe $b$, can offer the entrepreneur the opportunity of reporting that the "bad" natural state has arisen. In this case, the entrepreneur could refuse to pay the bribe ( $b^{d}$ being the bribe requested by the tax inspector), or agree to pay the bribe and negotiate the amount with the inspector.

The State checks on the behavior of entrepreneurs and tax inspectors. Let $q \in[0,1]$ be the exogenous monitoring level implemented by the State; then $q$ is the probability of being detected, given that corruption has taken place. The entrepreneurs incur a punishment equal to $c k$ where $c \in[0,1] .{ }^{2}$ We assume that the entrepreneurs are not homogeneous agents, and more precisely, the $j$-th entrepreneur attributes a subjective value $c_{j} k$ to the objective punishment - depending on his own "shame effect" - when the corrupt transaction is detected. The entrepreneur, if detected, must pay taxes $t y$, reputation cost $c_{j}$, but he is refunded the cost of the bribe paid to the tax inspector ${ }^{3}$.

\subsection{The game: description and solution}

Given the model just described, the economic problem can be formalized by the following two-period game.

In what follows, we refer to the entrepreneur payoff by a superscript (1) and to the

\footnotetext{
${ }^{1}$ The inspector is assumed to have monopolistic power, meaning that an entrepreneur is seen by only one inspector and cannot turn to other inspectors to be treated differently.

${ }^{2}$ The punishment for the entrepreneur is not a constant, but rather a function of the investment. In this case too, based on the statements of Rose - Ackerman (1999): "On the other side of the corrupt transaction, a fixed penalty levied on bribers will lower both the demand for corrupt services and the level of bribes. However, it will have no marginal impact once the briber passes the corruption threshold. To have a marginal effect, the penalties imposed on bribe payers should be tied to their gains (their excess profits, for example)". pp. 55.

${ }^{3}$ This assumption can be more easily understood when there is extortion by the tax inspector rather than corruption.
} 
inspector payoff by a superscript (2): they represent respectively the first and the second element of the payoff vector $\underline{\pi}_{i}, i=1,2,3,4$.

At the outset of the game, Nature decides in which state the entrepreneurs find themselves with their consequent level of activity.

(1) In the first stage of the game, the tax inspector checks the entrepreneurs' production. If a "bad" natural state occurs, then the tax inspector reports that no tax is owed and in this case, the game ends. Otherwise, if there is a "good" natural state, the tax inspector decides whether to ask for the bribe $b^{d}$ and to report that the "bad" natural state has arisen, and that the entrepreneur need not pay any tax.

(1.1) If $b^{d}=0$ no bribe is asked for, the payoff vector for the entrepreneurs and tax inspectors is:

$$
\underline{\pi}_{2}=(a k(1-t), w)
$$

The game ends in the equilibrium without corruption.

(1.2) Otherwise, let $b^{d}>0$ be the positive bribe asked for by the tax inspector, the game continues to stage two.

(2) At stage two the entrepreneur decides whether to negotiate the bribe or turn it down.

(2.1) If the entrepreneur refuses the bribe, then the payoff vector is given by:

$$
\underline{\pi}_{3}=(a k(1-t), w)
$$

Then in this case, the game ends. There is no penalty for the tax inspector.

(2.2) Otherwise the negotiation starts and the two parties will find the bribe corresponding to the Nash solution to a bargaining game $\left(b^{N B}\right)$ so the game ends. This bribe is the outcome of a negotiation between the inspector and the entrepreneur, who will be assumed to share a given surplus. The payoffs will depend on whether the inspector and the entrepreneur are detected (with probability $q$ ) or not detected (with probability $(1-q)$ ). There is no penalty for the tax inspector who is detected. ${ }^{4}$

If the entrepreneur decides to pay the bribe, the expected payoff vector is given by:

$$
\underline{\pi}_{4}=\left(a k(1-q t)-c_{j} k q-(1-q) b, w+(1-q) b\right)
$$

\footnotetext{
${ }^{4}$ The results do not depend on the existence of a cost for the tax inspector who is corrupted and detected.
} 
The game ends in the equilibrium with corruption and evasion.

We first determine the equilibrium bribe $b^{N B 5}$.

Proposition 2.1. Let $q \neq 1 .^{6}$ Then there exists a unique non negative bribe $\left(b^{N B}\right)$, as the Nash solution to a bargaining game, given by:

$$
b^{N B}=\mu\left[a k t-\frac{q k c_{j}}{(1-q)}\right] .
$$

where $\mu \equiv \frac{\varepsilon}{\varepsilon+\beta}$ is the share of the surplus that goes to the tax inspector and $\beta$ and $\varepsilon$ are the parameters that can be interpreted as the bargaining strength measures of the entrepreneur and the tax inspector respectively.

As a consequence of the model, if we assume that the tax inspector and the entrepreneur share the surplus on an equal basis, then we arrived at the standard Nash case, when $\varepsilon=\beta=1$. In this case the bribe is:

$$
b^{N B}=\frac{a k t}{2}-\frac{q k c_{j}}{2(1-q)} .
$$

In other words, the bribe represents 50 percent of the saving which comes from not paying taxes, net of reputation cost for the entrepreneur, if he is found out.

We will refer hereafter to the symmetry of the standard Nash bribe and study explicitly our problem for $\mu=\frac{1}{2}$.

The payoff vector is given by:

$$
\underline{\pi}_{4}=\left(a k-\frac{a k t(1+q)}{2}-\frac{c_{j} k q}{2}, w+\frac{a k t(1-q)}{2}-\frac{c_{j} q k}{2}\right)
$$

We now discuss the behavior of the equilibrium bribe in (5) with respect to the tax rate and monitoring level.

(1) Bribe vs tax rate. By analyzing this derivative we observe that:

$$
\frac{\partial b^{N B}}{\partial t}=\frac{a k}{2}>0
$$

\footnotetext{
${ }^{5}$ See Appendix A for the proof.

${ }^{6}$ If $q=1$ this stage of the game is never reached.

${ }^{7}$ In an asymmetric Nash bargaining solution, the surplus is shared unequally between the tax inspector and the taxpayer and thus the bribe paid to the inspector increases as the inspector's bargaining strength increases, expressed as $\varepsilon$. In fact, by computing this derivative we observe that:

$$
\frac{\partial b^{N B}}{\partial \mu}=a k t-\frac{q k c}{(1-q)}>0 .
$$

Increasing the bargaining power of the tax inspector increases the bribe which he can obtain.
} 
Therefore, increasing the tax rate also increases the potential surplus that the tax inspector and entrepreneur can share, thus increasing the bribe;

(2) Bribe vs monitoring level. In this case, we have:

$$
\frac{\partial b^{N B}}{\partial q}=-\frac{k c_{j}}{2(1-q)^{2}}<0
$$

Therefore, increasing monitoring reduces the potential surplus that the tax inspector and entrepreneur can share, thus reducing the bribe.

By solving the static game, we can prove the following proposition: ${ }^{8}$

Proposition 2.2. Let $0 \leq \frac{q c_{j}}{a(1-q)}=t^{*} \leq 1 .^{9}$ Then,

(a) if $t \in\left[0, t^{*}\right)$ the $j$-th entrepreneur will find it worthwhile to be honest and then the game ends with the payoff vector:

$$
\underline{\pi}_{2}=(a k(1-t), w)
$$

(b) if $t \in\left[t^{*}, 1\right]$ the $j$-th entrepreneur will find it worthwhile to be corrupt and then the game ends with the payoff vector:

$$
\underline{\pi}_{4}=\left(a k-\frac{a k t(1+q)}{2}-\frac{c_{j} k q}{2}, w+\frac{a k t(1-q)}{2}-\frac{c_{j} q k}{2}\right) .
$$

Depending on the value of the tax rate $t$, two sub-game perfect Nash equilibria can be found:

- If $t<t^{*}$, what the entrepreneur obtains by evading taxes is not enough to make up for his own expected reputation cost. With this in mind, the tax inspector will not ask the entrepreneur for a bribe. The game, therefore, finishes with the entrepreneur paying taxes. There is no sufficient margin for agreeing on a positive bribe with the tax inspector;

- If $t \geq t^{*}$, the entrepreneur finds it worthwhile to start a negotiation with the tax inspector. Thus the surplus to be shared between the entrepreneur and the inspector will keep a negotiation going, the outcome of which is the bribe corresponding to the Nash solution to a bargaining game.

\footnotetext{
${ }^{8}$ See Appendix B for the proof.

${ }^{9}$ We are assuming that $q c_{j} \leq a(1-q)$ that is, the cost of corruption expected by the entrepreneur is lower than the relevant benefits expected.
} 
In order to extend these considerations, we also analyze the solution of the game with respect to reputation cost $c_{j}$. Define

$$
c^{*}:=\frac{a t(1-q)}{q} .
$$

If $t \geq t^{*}$, then $c_{j} \leq c^{*}$; if $t<t^{*}$, then $c_{j}>c^{*} . c^{*}$ is assumed to be an honesty threshold. Moreover, since by definition $c^{*} \in[0,1]$, then there exists a minimal threshold for the monitoring activity

$$
q^{\circ}:=\frac{a t}{a t+1}
$$

such that $q \geq q^{\circ}$. Thus, the honesty threshold $c^{*}$ is well defined when the monitoring level is great enough. We will suppose $q \geq q^{\circ}$ in the remaining part of the paper.

Tax revenues depend on the hypothesis made about the distributional cost: if the specific $j$-th reputation cost is lower than $c^{*}$, the entrepreneur finds it worthwhile to evade all taxes; vice versa, if the $j$-th entrepreneur's reputation cost is greater than $c^{*}$ then the entrepreneur will be honest.

The cumulative density of probability defines the distribution of individual costs $F\left(c_{j}\right)$, where $j$ is the specific entrepreneur. We assume that the distribution of entrepreneurs' costs is of the Kumaraswamy type with real parameters $\alpha_{1}$ and $\alpha_{2}$. This choice is driven by two facts: first of all, the Kuramaswamy distribution belongs to the huge family of two-parameter probability laws. Thus, the choice of the Kuramaswamy distribution is not restrictive. Moreover, and differently from the other two-parameter distributions (the most famous being Beta distribution) we have an explicit formula for the cumulative density function and thus mathematical tractability.

The cumulative density function for the costs is:

$$
F\left(c_{j}\right)=\int_{0}^{c_{j}} \alpha_{1} \alpha_{2} c^{\alpha_{1}-1}\left(1-c^{\alpha_{1}-1}\right)^{\alpha_{2}-1} d c=1-\left(1-c_{j}^{\alpha_{1}}\right)^{\alpha_{2}} .
$$

Heterogeneity imposes that every entrepreneur will have a different reputation cost $c_{j}$, and the entrepreneur's behavior is assumed to be influenced by his own cost $c_{j}$, as evidence suggests.

The fraction of corrupted entrepreneurs i.e. with a shame cost $c_{j} \leq c^{*}$ is given by

$$
F\left(c^{*}\right)=1-\left(1-\left(c^{*}\right)^{\alpha_{1}}\right)^{\alpha_{2}}
$$

Analogously, we have that

$$
1-F\left(c^{*}\right)=\left(1-\left(c^{*}\right)^{\alpha_{1}}\right)^{\alpha_{2}}
$$


is the fraction of honest entrepreneurs, i.e. with a shame cost $c_{j}>c^{*}$.

Substituting (9) in (12) and (13), we obtain the fraction of corrupted and honest entrepreneurs respectively:

$$
F\left(c^{*}\right)=1-\left[1-\left(\frac{a t(1-q)}{q}\right)^{\alpha_{1}}\right]^{\alpha_{2}}
$$

and

$$
1-F\left(c^{*}\right)=\left[1-\left(\frac{a t(1-q)}{q}\right)^{\alpha_{1}}\right]^{\alpha_{2}}
$$

We can analyze the behavior of corruption (takes as the number of corrupt entrepreneurs) with respect to the tax rate and monitoring level.

(1) Corruption vs tax rate. By analyzing this derivative we observe that, if $\alpha_{2}>1$, then:

$$
\frac{\partial F\left(c^{*}\right)}{\partial t}=\frac{\alpha_{1} \alpha_{2} a(1-q)}{q}\left[1-\left(\frac{a t(1-q)}{q}\right)^{\alpha_{1}}\right]^{\alpha_{2}-1}\left(\frac{a t(1-q)}{q}\right)^{\alpha_{1}-1}>0 .
$$

Therefore, increasing the tax rate also increases the potential surplus that the tax inspector and entrepreneur can share, thus increasing corruption, irrespective of the specific distribution of shame cost;

(2) Corruption vs monitoring level. In this case, if $\alpha_{2}>1$, then:

$$
\frac{\partial F\left(c^{*}\right)}{\partial q}=-\frac{\alpha_{1} \alpha_{2} a t}{q^{2}}\left[1-\left(\frac{a t(1-q)}{q}\right)^{\alpha_{1}}\right]^{\alpha_{2}-1}\left(\frac{a t(1-q)}{q}\right)^{\alpha_{1}-1}<0 .
$$

Therefore, increasing monitoring reduces the potential surplus that the tax inspector and entrepreneur can share, thus reducing corruption.

We also notice that corruption does not depend on the distribution of the surplus between the inspector and the tax evader, but only on the amount of the surplus $\tau$. On an aggregate level, the tax revenues, with a tax rate fixed at $t$, will be equal to the tax paid by those who find themselves in a positive natural state (with probability $(1-\delta))$ and who have a reputation cost which leads them to be honest, and those who are corrupt, but are discovered in the act of corruption:

$$
E(t, q)=a t k\left[1-\left(1-\left(c^{*}\right)^{\alpha_{1}}\right)^{\alpha_{2}}\right](1-\delta) q+a t k\left(1-\left(c^{*}\right)^{\alpha_{1}}\right)^{\alpha_{2}}(1-\delta) .
$$

The presence of the reputation costs in (16) and of an honesty threshold $c^{*}$ allows us to distinguish honest entrepreneurs, who pay taxes, from the others. ${ }^{10}$

\footnotetext{
${ }^{10}$ If $t=1$, then it is reasonable to suppose that all entrepreneurs are corrupt, independently on the reputation cost threshold $c^{*}$. In this case the tax revenues are paid only by those entrepreneurs who have been found out: $E(1)=(1-\delta) a k q$.
} 
By substituting $c^{*}$ with its expression in (9), a straightforward computation allows us to rewrite $E(t, q)$ in (16) as follows:

$$
E(t, q)=(1-\delta) a t k\left\{q-(q-1)\left[1-\left(\frac{a t(1-q)}{q}\right)^{\alpha_{1}}\right]^{\alpha_{2}}\right\}
$$

\subsection{Comparative statics}

We would now like to provide a sensitivity analysis of $E$ with respect to $t$ and $q$. We perform a numerical analysis of the behavior of $E$ with respect to $t$ and $q$, in order to avoid the complexity of the closed form results and propose a more intuitive description of the real situation.

We set $\delta=0.5, k=1$, three different values for the capital productivity parameter: $a=0.5 ; 1 ; 2$, and three different distributions of the reputation costs $\left(\alpha_{1}=\alpha_{2}=2\right.$; $\alpha_{1}=2$ and $\alpha_{2}=5 ; \alpha_{1}=5$ and $\alpha_{2}=2$ ). When $\alpha_{1}=\alpha_{2}=2$, we have symmetry among the agents with respect to the reputation costs; if $\alpha_{1}=5$ and $\alpha_{2}=2$, then we observe asymmetry on the right-hand side of the distribution curve, which means a high level of reputation costs and describes populations with a "high shame effect"; the case $\alpha_{1}=2$ and $\alpha_{2}=5$ is the converse: the asymmetry is on the left-hand side of the distribution curve, and we have populations with a "low shame effect".

Generally, ceteris paribus, we observe three effects of the tax rate on tax revenues:

(1) as the tax rate increases, revenues increase, because those who are still honest pay more taxes;

(2) as the tax rate increases, the number of honest entrepreneurs decreases and thus revenues go down. Moreover, the number of corrupted entrepreneurs increases and the number of undiscovered entrepreneurs grows;

(3) as the tax rate increases, revenues from entrepreneurs discovered in corrupt transactions increase.

As we can observe (see Figures 1-2), some considerations emerge from the results of our analysis.

\section{Insert Figures 1 and 2 about here}

For "low shame" countries (see Figure 1), revenues increase as $t$ increases. This behavior explains that revenues grow with $t$ because the reduction of tax revenues due to (2) is lesser than the positive terms due to the sum of (1) and (3). In detail, we have that, if a low level of the monitoring parameter $q$ is fixed, there exists a tax 
rate threshold $\bar{t}_{1, q}$ such that $E(t, q)$ is concave for $t<\bar{t}_{1, q}$ and convex otherwise. The shape of the surface describes this change in concavity more remarkably when $a$ is small. The growth of tax revenues is faster for high values of the tax rates, since most populations with low shame do not appreciate the reduction in the tax rate, if monitoring activity is missing. Thus, the sum between the positive terms due to (1) and (3) and the negative term due to (2) increases, and $\bar{t}_{1, q}$ can be viewed as a "relevant tax rate". When $q$ is big enough, we do not observe a change in the behavior of the population, which is globally indifferent to the tax rate. The function $E(t, q)$ does not present changes in concavity, and seems to be linear with respect to $t$. This fact describes the evidence that a properly monitored population pays taxes, even if the individuals have low shame. Therefore, for high monitoring levels, our analysis does not allow us to distinguish populations with low or high shame effects, and the tax revenues generally grows with $t$.

For "high shame" countries (see Figure 2), when the monitoring activity is low, the tax revenues are bigger those the ones in countries with a low shame effect, as they evidently should be. Nevertheless, if a small value of $q$ is fixed, there is a tax rate threshold $\bar{t}_{2, q}$ such that $E(t, q)$ decreases for $t>\bar{t}_{2, q}$ and increases for $t<\bar{t}_{2, q}$. Hence, the tax rate $\bar{t}_{2, q}$ is a global maximum of $E(t, q)$ with respect to $t$. This fact is in agreement with the evidence that an excessive increase in tax rate implies that a large part of the population "becomes dishonest". The effect of (1) and (3) loses quantitative relevance with respect to the negative terms (2), and the tax revenues invert their tendency: from growing to falling. If $q$ is fixed at a small enough level, then $\bar{t}_{2, q}$ is a Laffer-type optimal tax rate, and $E\left(\bar{t}_{2, q}, q\right)$ is the Laffer-type optimal tax revenues that a country can obtain. Also in this case, the phenomenon is more remarkable when $a$ is small. If $q$ is big enough, as we said above, the behavior of the tax revenues surface is the same as that in the low shame countries.

For "middle shame" countries, the tax revenues behave analogously to the case of the high shame countries, but the surface is smoother. The aggregate effect of (1) and (3) is greater than the reduction effect of (2) for small tax rates.

We proceed now to the analysis of revenues $E$ with respect to the parameter $q$, by formalizing the following result ${ }^{11}$.

Proposition 2.3. Fix $t \in[0,1]$. If $\alpha_{2}>1$, then $E(t, q)$ is increasing w.r.t. $q$, for each $t \in[0,1]$.

Proposition 2.3 provides a general result: increasing monitoring reduces the potential surplus that the tax inspector and the entrepreneur can share. Therefore corruption

\footnotetext{
${ }^{11}$ See Appendix $\mathrm{C}$ for the proof.
} 
reduces and revenues increase.

\section{Policy consideration}

In this section we use the results derived above to assess the normative implications of our model of tax evasion and corruption. The results of our model are certainly influenced by two important assumptions relating to the behavior of the State.

- No budget constraint is included and, therefore, several very concrete requirements have been excluded, regarding those countries which are obliged to adhere to the agreement for stability and growth and a well-balanced State budget.

- Public expenditure is not productive but is used exclusively for the inspectors' wages. If this were not so, greater fiscal income might lead to lower accumulation for the entrepreneur, but to higher productive costs for the State. Therefore, an important issue might be whether private expenditure (entrepreneurs' investment) is more productive than public spending.

Let us briefly summarize the findings obtained so far. If the tax rate increases, then tax revenues change, depending on the shame costs. Simultaneously, the corruption level also grows, because the number of corrupted entrepreneurs increases.

The State could choose to achieve different policy objectives in this context. If the State is operating over the short term, its goals could be to maximize tax revenues or eradicate corruption. We have demonstrated that the tax rate influences on the revenues and the level of corruption. We have, in fact, shown that corruption increases as the tax rate increases. Therefore, the State could choose to achieve the following policy objectives: maximize tax revenues or weed out corruption.

As there is no equilibrium which maximizes tax revenues with zero corruption, the State must choose what, on the basis of its own preferences, is best for society:

- if the State wants to maximize tax revenues, depending on the shame effect (low or high), it has to set:

$(*)$ in a low-shame country, a tax rate greater than $\bar{t}_{1, q}$, because beyond this value, tax revenues increase - as the tax rate increases - at an increasing rate;

$(*)$ in a high-shame country, a tax rate equal to $\bar{t}_{2, q}$ because this value is a global maximum of $E(t, q)$ with respect to $t$.

In both cases there is corruption in the economy. 
- if the State wants to weed out corruption, it has to set the tax rate at $t=0$. In this way, there are no incentives for corruption. In such an equilibrium, the State does not receive revenues. This fact explains the persistence of corruption.

Remark 3.1. Let us extend the model in order to consider an objective prison sentence $m$ for the entrepreneur and the tax inspector, due to tax evasion. We find a threshold value of tax rate in correspondence of which there is not corruption and the tax revenues are different from zero. Indeed, the introduction of a prison sentence reduces the surplus of the entrepreneur of being corrupt. More precisely, the number of corrupt entrepreneurs becomes:

$$
F\left(c^{*}\right)=1-\left[1-\left(\frac{a t(1-q)}{q}-m\right)^{\alpha_{1}}\right]^{\alpha_{2}},
$$

and therefore there exists a critical tax rate $t_{m}^{\circ}=\frac{m q}{a(1-q)} \neq 0$ which weeds out corruption.

\section{Conclusions}

The present paper provides a study of the behaviour of fiscal revenues, where there is evasion and fiscal corruption. In our model, the relationship between the tax rate and tax revenues depends on the "inner honesty" of society. We demonstrate that a Laffer-type optimal tax rate exists only in countries with a "high shame" effect: in this case there is a global maximum of fiscal revenues with respect to the tax rate. In countries with a "low shame" effect, tax revenues grow as the tax rate does. More specifically, there is a threshold value for the tax rate where the increasing rate of the tax revenues begins to reduce.

From a normative point of view, an optimal level of taxation exists both for "high shame" and "low shame" countries, which permits governments to maximize fiscal revenues. 


\section{A Appendix: The Nash Bargaining bribe}

Let $\underline{\pi}_{\Delta}=\underline{\pi}_{4}-\underline{\pi}_{3}=\pi_{\Delta}^{(1)}, \pi_{\Delta}^{(2)}$ be the vector of the differences in the payoffs between the case of agreement and disagreement between inspector and entrepreneur about the bribe. In accordance with generalized Nash bargaining theory, the division between two agents will be solved by the following optimization problem:

$$
\max _{b \in \Re^{+}}\left[\pi_{\Delta}^{(1)}\right]^{\beta} \cdot\left[\pi_{\Delta}^{(2)}\right]^{\varepsilon}
$$

in formula

$$
\max _{b \in \Re^{+}}\left[a k(1-t q)-c_{j} k q-(1-q) b-a k(1-t)\right]^{\beta}[w+(1-q) b-w]^{\varepsilon}
$$

that is the maximum of the product between the elements of $\underline{\pi}_{\Delta}$ and where $[(a k(1-$ $t)), w]$ is the point of disagreement, i.e. the payoffs that the entrepreneur and the inspector respectively would obtain if they did not come to an agreement. It is now easy to check that the tax inspector gets a share $\mu=\frac{\varepsilon}{\varepsilon+\beta}$ of the surplus $\tau$, i.e. the bribe is $b=\mu \tau$. The surplus $\tau$ is the saving which comes from not paying taxes, net of reputation cost that awaits the entrepreneur if he is found out: $\tau=a k t-\frac{q c_{j} k}{(1-q)}$. Then the bribe $b^{N B}$ is an asymmetric (or generalized) Nash bargaining solution and is given by:

$$
b^{N B}=\mu\left[a k t-\frac{q k c_{j}}{(1-q)}\right]
$$

that is the unique equilibrium bribe in the last subgame, $\forall q \neq 1$.

\section{B Appendix: Solution to the static game}

The static game is solved with the backward induction method, which allows us to identify the equilibria. Starting from stage 2, the entrepreneur needs to decide whether to negotiate with the inspector. Both payoffs are then compared, because the inspector asked for a bribe.

Stage II At stage two the entrepreneur negotiates the bribe if, and only if

$$
\begin{gathered}
\underline{\pi}_{4}^{(1)} \geq \underline{\pi}_{3}^{(1)} \Rightarrow \\
{\left[a k\left[1-\frac{t(1+q)}{2}\right]-\frac{k q c_{j}}{2}\right] \geq a k(1-t) \Rightarrow} \\
t \geq \frac{q c_{j}}{a(1-q)}=t^{*}
\end{gathered}
$$


Stage I Going up the decision-making tree, at stage one the tax inspector decides whether to ask for a positive bribe or not.

- Let $t \geq \frac{q c_{j}}{a(1-q)}=t^{*}$ then the tax inspector knows that if he asks for a positive bribe, the entrepreneur will accept the negotiation, and the final bribe will be $b^{N B}$. Then at stage one, the tax inspector asks for a bribe if, and only if

$$
\begin{gathered}
\underline{\pi}_{4}^{(2)}>\underline{\pi}_{2}^{(2)} \Rightarrow \\
w+\frac{\operatorname{akt}(1-q)}{2}-\frac{q k c_{j}}{2}>w
\end{gathered}
$$

that is:

$$
t \geq \frac{q c_{j}}{a(1-q)}=t^{*}
$$

If $t \geq t^{*}$, then the tax inspector will ask for the bribe $b^{N B}$ and the entrepreneur will accept.

- Let $t<\frac{q c_{j}}{a(1-q)}=t^{*}$ then the tax inspector knows that the entrepreneurs will not accept any possible bribe, so he will be honest and he will ask the entrepreneurs for tax payment.

\section{Appendix: Tax revenues vs tax rate}

The function $E$ admits continuous partial derivative w.r.t. $q$, and so we have to show that $\frac{\partial E(t, q)}{\partial q}>0$. A simple computation gives

$$
\frac{\partial E(t, q)}{\partial q}=\underbrace{(1-\delta) a t k}_{=\mathcal{I}_{1} \cdot\left\{1-\mathcal{I}_{2} \cdot \mathcal{I}_{3}\right\}}\{1-\underbrace{\left[1-\left(\frac{a t(1-q)}{q}\right)^{\alpha_{1}}\right]^{\alpha_{2}-1}}_{(25)} \cdot \underbrace{\left[1-\left(\frac{a t(1-q)}{q}\right)^{\alpha_{1}}\left(1+\frac{\alpha_{1} \alpha_{2}}{q}\right)\right]}\}=
$$

and the definition of the $\mathcal{I}$ 's reflects the underbrace symbols.

$\mathcal{I}_{1}$ is always greater than 0 . If $\alpha_{2}>1$, then $\mathcal{I}_{2} \in(0,1)$; moreover, $\mathcal{I}_{3}<1$. Hence, we have $\frac{\partial E(t, q)}{\partial q}>0$.

\section{References}

[1] Acconcia A, D'Amato M, Martina R. Tax Evasion and Corruption in Tax Administration. Public Economics. 0310001, Economics Working Paper Archive at WUSTL, 2003. 
[2] Allingham GM, Sandmo A. Income Tax Evasion: A Theoretical Analysis. Journal of Public Economics 1972;1; 323-338.

[3] Barreto RA, Alm J. Corruption, Optimal Taxation, and Growth. Public Finance Review 2003;31(3); 207-240.

[4] Besley T, Mclaren J. Taxes and Bribery: the Role of Wage Incentives. Economic Journal 1993;103; 119-141.

[5] Becker SG. Crime and Punishment: An Economic Approach, Journal of Political Economy 1968;76; 169-217.

[6] Chand SK, Moene KO. Controlling Fiscal Corruption, World Development 1999;27; 1129-1140.

[7] Chander P, Wilde L. Corruption in Tax Administration. Journal of Public Economics 1992;49; 333-349.

[8] Easterly W. The Elusive Quest for Growth. MIT Press, 2002.

[9] Fisman RJ, Wei SJ. Tax rate and tax Evasion: Evidence from Missing Imports in China. CEPR Discussion Paper, no. 3089, 2001.

[10] Graetz MJ, Reinganum JF, Wilde L. The Tax Compliance Game: towards an Interactive Theory of law Enforcement. Journal of Law, Economics and Organization 1986;38; 1-32.

[11] Hindriks J, Keen M, Muthoo A. Corruption, Extortion and Evasion. Journal of Public Economics 1999;74; 394-430.

[12] Mookherejee D, Png PL. Corruptible Law Enforcers: How should they be compensated? Economic Journal 1995;105; 145-159.

[13] Mookherejee D. Incentive Reforms in Developing Country Bureaucracies. Lesson from Tax Administration, Paper prepared for the Annual Bank Conference on Development Economics, Washington, D.C: The World Bank, 1997.

[14] Polinsky AM, Shavell S, Corruption and Optimal Law Enforcement. Journal of Public Economics 2001;81; 1-24.

[15] Rose Ackerman S, The Economics of Corruption. Journal of Public Economics $1975 ; 187-203$. 
[16] Rose Ackerman S, Corruption. A Study in Political Economy. Academic Press; 1978.

[17] Sanyal A, Gang IN, Goswami O, Corruption, Tax Evasion and the Laffer Curve 2000;105; 61-78.

[18] Shleifer A, Vishny R. Corruption. The Quarterly Journal of Economics; 1993; 599-617.

[19] Slemrod J, Yitzhaki S, Tax Avoidance, Evasion, and Administration, NBER Working Paper no. W7473, 2000.

[20] Stigler JG. The Optimum Enforcement of Laws, Journal of Political Economy 1970;78; 526-536.

[21] Tanzi V, Davoodi HR. Corruption, Growth and Public Finances, IMF Working Paper, WP/00/182, 2000. 